\title{
Assessment of soil biocontamination with toxocara eggs in urbanized ecosystems
}

\author{
Olga Maslennikova ${ }^{1}$, Viktoriya Erofeeva $^{2,3, *}$ \\ ${ }^{1}$ Vyatka State Agricultural Academy, 610017 Kirov, Russia \\ ${ }^{2}$ Moscow Technical University of Communications and Informatics, 111024 Moscow, Russia \\ ${ }^{3}$ Peoples Friendship University of Russia (RUDN University), Faculty of Ecology, 6 Miklukho- \\ Maklaya Street, Moscow, 117198, Russian Federation
}

\begin{abstract}
Toxocariasis in the Russian Federation is the most dangerous of the common helminthiases that can affect dogs or cats. Toxocariasis is a zoonotic geohelminthiasis, which is naturally transmitted from vertebrates to humans and poses a threat to people as a source of infection in megacities. In order to study the prevalence of toxocars among domestic and stray dogs living in the urbanized ecosystems of the Kirov region, the study of dog excrement by the flotation method has been carried out for 3 years. The results of the research show that, on average, in the village of Zagarye of the Yuryansk region, the amount of the dogs infected with toxocariasis is $64 \%$, in the yards and children's playgrounds $-76.6 \%$. In the parks of Kirov, the amount of infected dogs is $28.0 \pm 2.3 \%$ and $21.0 \pm$ $3.6 \%$, respectively. The calculated values of soil biocontamination in the parks of Kirov per day are 1948.64 and 1205.0 thousand eggs, in the village of Zagarye - 161,014.0 thousand Toxocara eggs. During the year, these values reach astronomical values: 711253,6 thousand, 439854.0 thousand and 58770110.0 thousand toxocara eggs, respectively. The high prevalence rates of infection with Toxocara spp. among stray and domestic animals create conditions that can lead to constant pollution of urbanized ecosystems and cause a tense ecological and epidemic situation in the city.
\end{abstract}

\section{Introduction}

Geohelminthiasis is one of the first in the world in terms of prevalence.

In Russia, ascariasis and toxocariasis take second place considering prevalence and incidence among the population. Soil contamination with eggs of geohelminths (such as Toxocara spp.) in urbanized ecosystems has become a serious problem in recent years. The incidence of toxocariasis among children and adults directly depends on soil contamination with toxocara helminth eggs, which are spread by dogs. In places where there is a large number of dogs (rural settlements, urban-type settlements and even cities), the level of soil biocontamination increases. In the Tyumen region, according to the Veterinary Directorate, of the total number of soil (sand) samples examined, toxocar eggs were found in $61 \%$; in children's playgrounds during the period from 2009-2011 Toxocar eggs were found in $85 \%$

\footnotetext{
* Corresponding author: erofeeva-viktori@mail.ru
} 
of soil samples, in $8.4 \%$ of samples - from surface water bodies, in $3.3 \%$ of wastewater samples, in $3.3 \%$ of vegetable samples. A high level of soil contamination with helminth eggs was in the city of Pyatigorsk. Toxocara eggs were found in $41 \%$ of soil samples [1-4]. The experiment showed that up to $80.1 \%$ of eggs died on the soil surface in July, and $20.2 \%$ - at a depth of $5 \mathrm{~cm} \mathrm{[5-9].}$

According to the Department of Rospotrebnadzor in the Kirov region, in 2017 toxocariasis in the population was detected in almost all districts of the Kirov region. The highest prevalence rates of infection were registered in the following districts of the region (per 100 thousand population): Urzhum district - 24.5; Kilmez district - 24.5; Falensky district -24.5; Bogorodsky district - 23.2; Verkhnekamsky -23.5; Nagorsky district -22.7 Murashinsky district - 17.5. Yuryansk region - 7.8; least of all in Kirov - 0.4. Currently, the tendency for the spread of toxocariasis is somewhat decreasing, but remains at a dangerous level for humans.

\section{Materials and methods}

The study was conducted in 2017-2020 at the laboratory of the Vyatka State Agricultural Academy in Kirov. In total, we studied and analyzed 400 random faecal samples from domestic and stray dogs in two settlements: the city of Kirov and the village of Zagarye, Yuryansk region. The samples of the studied animal excrement were delivered to the laboratory in sealed plastic bags with the date and place of collection marked on them. Animal feces were examined by the flotation method [10-11]. Microscopic studies were carried out using a biological microscope Biolam with a magnification of $20 \times 10,20 \times 40$. To determine the level of biocontamination, the formula for calculating the release of dog excrement into the environment was used:

$$
\mathrm{M}=\sum(\mathrm{N} * \mathrm{~m} * \mathrm{~g} * \mathrm{C})
$$

where $\mathrm{N}$ is the number of dogs, $\mathrm{m}$ is the weight of one dog, $\mathrm{g}$ is the norm for excreta generation $(0.07 \%), \mathrm{C}$ is the period of keeping the dog.

\section{Results}

In the city of Kirov, the dog excrement from two parks located in the city center was studied. The contamination of dog excrement with T. canis eggs in Kirov in these parks did not differ significantly: in the park named after Kirov $-28.0 \pm 2.3 \%$, in the park of the 50th Anniversary of the Komsomol $-21.0 \pm 3.6 \%$. The average prevalence rate of toxocara infection (EI) among dogs was $24.5 \pm 2.95 \%$. The average number of dogs per day of the study was - 75 individuals in the park named after Kirov, 63 individuals - in the park of the 50th Anniversary of the Komsomol [12-13].

In the village of Zagarye (Yuryansk district) of the Kirov region, where our research was conducted, there is a large number of dogs since the majority of the population are hunters and their families.

According to the survey carried out among respondents in the village, there are 3-5 dogs per family, as for the breed, $90 \%$ of all dogs are huskies. According to the data obtained from the village council, the number of hunting dogs in the village was 1947 . The density of dogs in the village is 10.5 individuals per hectare. Dogs are not kept on a leash, only a small number of them are kept indoors, but most of the day all the animals are free to roam the streets of the village.

There are no designated areas to walk the dogs and there is unauthorized pollution of the environment with dog feces. To determine biocontamination, we examined the dog 
excrement collected in the area: on the streets, in yards, public places, children's playgrounds and parks.

The analysis of excrement revealed a high percentage of dogs infected with $T$. canis eggs $-64.0 \%$. The highest percentage of dogs infected with T.canis eggs was registered in children's playgrounds and yards $-76.6 \%$; in parks $62.0 \%$ and $50.0 \%$ in the center of the village (outskirts of roads, nearby shops) (Picture 1).

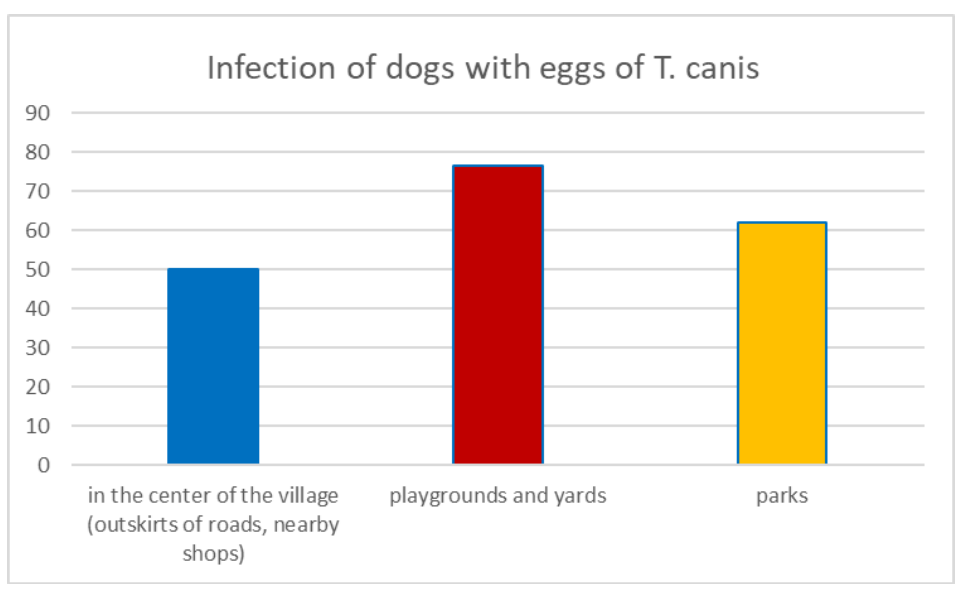

Fig.1. Infection of dogs with eggs of T. canis

Since the prevalence rates of toxocariasis among animals is high (60-70\%), every day dogs, excreting feces, pollute the environment with millions of eggs. The magnitude of biocontamination is also influenced by the factor that the female $T$. canis lays more than 20 thousand eggs per day which enter the environment with animal feces and mature in the soil, where they are able to maintain their viability and invasiveness for a long time. According to D.Yu. Derkacheva (2014), the average number of T. canis eggs in $1 \mathrm{~g}$ of feces is 256.4 eggs [14].

To determine soil biocontamination with toxocara eggs, we calculated the number of dogs infected with toxocariasis in the parks of Kirov and the village of Zagarye, Yuryansk district. The obtained data on biocontamination is presented in the table.

Table 1. Biological soil contamination with eggs of T. canis

\begin{tabular}{|l|c|c|c|}
\hline Sampling location & $\begin{array}{l}\text { Park named after } \\
\text { Indicator }\end{array}$ & $\begin{array}{l}\text { Park of the 50th } \\
\text { Anniversary of } \\
\text { S.Me Komsomol }\end{array}$ & $\begin{array}{l}\text { The village of } \\
\text { Zagarye }\end{array}$ \\
\hline $\begin{array}{l}\text { Number of positive excrement } \\
\text { samples, \% }\end{array}$ & $28 \pm 2.3$ & $21 \pm 3.6$ & $64.0 \pm 0.4$ \\
\hline $\begin{array}{l}\text { Number of infected dogs } \\
\text { (individuals) }\end{array}$ & 21 & 13 & 1246 \\
\hline $\begin{array}{c}\text { The value of biocontamination } \\
\text { with T. canis per day (thousand } \\
\text { eggs) }\end{array}$ & 1948.64 & 439854.0 & 58770110.0 \\
\hline $\begin{array}{l}\text { The value of biocontamination } \\
\text { with T. canis per year (thousand } \\
\text { eggs) }\end{array}$ & 711253.6 & 1205.0 & 014.0 \\
\hline
\end{tabular}

To determine the level of biocontamination, we used the formula for calculating the amount of dog excrement entering the environment [10-11].

According to this formula, in the park named after Kirov $\mathrm{N}$ will be equal to the number of dogs infected with toxocars $(28 \pm 2.3 \%)$ which corresponds to 21 individuals. The mass 
of one dog under one year of age is on average $18 \mathrm{~kg}$ ( 0.018 tons). We calculated the amount of excreta released by infected dogs per day and per year. Substituting the values in the formula, we got the excreta yield per day $-18.9 \mathrm{~kg}$, per year $-6898.5 \mathrm{~kg}$. Taking into account the fact that $60 \%(11.3 \mathrm{~kg})$ of the dog excreta is urine, we get the excrement output per day, which is $7.6 \mathrm{~kg}$ and $2774 \mathrm{~kg}$ per year, respectively.

Considering that $1 \mathrm{~g}$ of $\mathrm{dog}$ feces contains up to 256.4 Toxocara eggs, we determined the level of contamination. Within one day in the studied area of the park named after S.M.Kirov dogs shed up to $1,948,640$ and during the year - 711 million 253 thousand 600 T. canis eggs.

Similar calculations were made for the park of the 50th Anniversary of the Komsomol and the village of Zagarye. For the park of the 50th Anniversary of the Komsomol, we determined the following value of biocontamination: dogs release up to 1 million 205 thousand T. canis eggs per day and up to 439 million 854 thousand eggs per year. In the village of Zagarye, dogs release up to 161 million 014 thousand T. canis eggs per day and up to 58 billion 770 million 110 thousand eggs per year.

\section{Discussion}

A large amount of infected dogs in the village of Zagarye of the Yuryansk district of the Kirov region is explained by the fact that there are a lot of dogs under the age of one year roaming the streets (on average 64\%) since each family of hunters keeps a bitch producing offspring every year. In addition, during the hunting period dogs can be injured and killed. Puppies are more susceptible to Toxocara transmission.

Transmission of Toxocara canis larvae to puppies occurs in different ways: transplacental and transmammary. Young and adult dogs more often become infected orally ingesting a paratenic host (small rodents, farm animals, as well as some invertebrates, for example, earthworms and cockroaches) $[4,12]$. In paratenic hosts, only somatic migration occurs, and larvae do not develop and remain at the level of the invasive larva.

It was revealed that in Tajikistan, a large amount of domestic dogs at the age of 4-8 years was infected with toxocars $-36.3 \%$, less dogs, $33.3 \%$ - at the age of 6 months -1 year, but the largest amount, 50\% - puppies before the age of 6 months. In Moscow, the prevalence rate of this infection among dogs is low: $2.43 \%$ in adult dogs, and $5.53 \%$ in puppies. This is due to the fact that domestic dogs were examined. In case of a high number of dogs, particularly if a lot of them are neglected, the problem of environmental pollution with the faeces of these animals, as well as with Toxocara eggs, becomes more and more acute.

Since the prevalence rate of the infection among animals is usually significantly high (up to $70 \%$ ), every day dogs, excreting feces, pollute the environment with millions of eggs. The female roundworm is capable of producing more than 200 thousand eggs per day, which enter the environment with animal feces, mature in the soil, where they are able to maintain their viability and invasiveness for a long time. According to parasitologists, 1 $\mathrm{g}$ of dog feces contains up to 10,000-15,000 toxocara eggs [15].

We used the data according to D.Yu. Derkacheva [14]: $1 \mathrm{~g}$ of dog feces contains 256.4 toxocara eggs, because it is comparable with our data when dealing with toxocar eggs. The figures presented by N.I.Tumolskaya [15] are characteristic of larger ascaris species - pork (Ascaris suum) and human (Ascaris lumbricoides).

The values of soil biocontamination we obtained directly depend on the number of stray dogs and the prevalence rate of infection with toxocars among them. 


\section{Conclusions}

The study revealed the breeding ground for toxocariasis in the urbanized territories of the Kirov region. This is confirmed by high prevalence rates of toxocar infection among dogs and a large number of stray dogs. In the village of Zagarye of the Yuryansk region the amount of dogs infected with toxocariasis averaged $64 \%$, and most of the infected feces were found in the yards and children's playgrounds $-76.6 \%$.

In the parks of Kirov, the prevalence rates of infection among dogs was $28.0 \pm 2.3 \%$ and $21.0 \pm 3.6 \%$. Dogs infected with toxocariasis, excreting feces, contaminate the soil in parks and children's playgrounds. The dedermined values of soil biocontamination in the parks of Kirov per day are 1948.64 and 1205.0 thousand eggs, in the village of Zagarye $161,014.0$ thousand eggs. During the year, these values skyrocket reaching 711253,6 thousand, 439854.0 thousand and 58770110.0 thousand toxocara eggs, respectively.

\section{References}

1. I. Zaichenko, Helminthiasis of carnivorous urban population: distribution, diagnosis, treatment (Stavropol State Agrarian University, Stavropol, 2012)

2. N. Luneva, N. Ponomarev, Bulletin Alt. GAU, 11, 130-133 (2014)

3. Y. Mayorova, V. Glebov, V. Erofeeva, S. Yablochnikov, B. Laver, E3S Web of Conf. 169, 04004 (2020)

4. O. Maslennikova, V. Erofeeva, E3S Web of Conferences 169, 04002 (2020)

5. I.A. Arkhipov, O.A. Zeynalov, L.M. Kokorina, D.A. Avdanina, S.V. Likhotina, Russian Veterinary J., 2, 26-30 (2005)

6. M.V. Guzeeva, The role and place of rare helminthiases in parasitic pathology in Russia (Sechenov Moscow Medical Academy, Moscow, 2009)

7. G. A. Kotelnikov, Helminthological studies of animals and the environment (1984)

8. L.V. Shishkanova, Toxocariasis in the south of Russia (Rostov Scientific Research Institute of Microbiology and Parasitology, Rostov, 2011)

9. S. Okoshi, M. Usui, Jpn. J. Vet. Sci, 30, 151-166 (1968)

10. Methods of sanitary-parasitological research (2000)

11. Guidelines for assessing the volume of production and consumption waste generation (2003)

12. V.V. Erofeeva, O.V. Maslennikova, Hygiene and sanitation, 8, 897-902 (2019)

13. V.V. Erofeeva, O.V. Maslennikova, Modern problems of science and education, 3, 573 (2015)

14. D.Y. Derkachev, Development of new technological methods of diagnostics and control measures for nematodes in carnivores (2014)

15. N.I. Tumolskaya, V.P. Sergiev, M.N. Lebedeva and others, Toxocariasis. Clinic. Diagnostics. Treatment. Prophylaxis (2004) 